\title{
Article \\ Correlation Analysis and Its Application on an Asymmetry Rotor Structure with Overhang
}

\author{
Shun Zhong ${ }^{1}{ }^{\mathbb{D}}$, Suxia Zhang ${ }^{1, *}$, Jie Yang ${ }^{2}$ and Yanan Zhang ${ }^{2}$ \\ 1 Department of Mechanics and Key Laboratory of Nonlinear Dynamics and Control, Tianjin University, \\ Tianjin 300072, China; shunzhong@tju.edu.cn \\ 2 Hebei Ruizhao Laser Remanufacturing Technology Stock Co., Ltd, Tangshan 064300, China; \\ 15081529322@163.com (J.Y.); zj15802@126.com (Y.Z.) \\ * Correspondence: zhangsux@tju.edu.cn
}

Citation: Zhong, S.; Zhang, S.; Yang, J.; Zhang, Y. Correlation Analysis and Its Application on an Asymmetry Rotor Structure with Overhang. Appl. Sci. 2021, 11, 11501. https://doi.org/ 10.3390/app112311501

Academic Editor: Ning $\mathrm{Hu}$

Received: 8 November 2021

Accepted: 29 November 2021

Published: 4 December 2021

Publisher's Note: MDPI stays neutral with regard to jurisdictional claims in published maps and institutional affiliations.

Copyright: (c) 2021 by the authors. Licensee MDPI, Basel, Switzerland. This article is an open access article distributed under the terms and conditions of the Creative Commons Attribution (CC BY) license (https:/ / creativecommons.org/licenses/by/ $4.0 /)$.

\begin{abstract}
Overhung rotors are widely used in the industrial field. However, compared with normal structure rotors, the prediction and control of overhung rotors cannot achieve good performance. The work aims to investigate the dynamical behaviours of an overhung rotor by means of correlation analysis, and find its possible application. In this work, based on a real type of rotor, the dynamic model of the rotor with overhang is established by means of the finite element method. Simulation of the dynamic model with different input positions and support stiffnesses is conducted. Based on the methodology of correlation analysis, by introducing a correlation parameter of a proportion of amplitude of measured signal and imbalance mass, the position which has most effect on the vibration is found. Meanwhile, an experiment on the same type of overhung rotor is carried out to validate the results. The numerical results and corresponding experimental results prove that the overhung node has the most effect on the vibration amplitudes of the measured points. Choosing the overhung node to add trial weight, the overhung rotor can be easily balanced. The theory provides an alternative approach to modal analysis which needs more knowledge of the system.
\end{abstract}

Keywords: overhang; asymmetry rotor; correlation analysis; rotor balancing

\section{Introduction}

Overhung rotors are found in many industrial applications. Many works on rotors with overhung design have been reported. For instance, electromagnetic motors [1-4], spindle in ultra-precision machine [5], turbine generator [6-13], compressor [14], and turbine power rotors [15] are rotor structures which must or may have overhung parts. Taking the turbine generator rotor as an example, the overhung parts always exist to implement the field winding. The mass and electromagnetic field of the overhung part would affect the dynamical behaviours of the rotor system conversely. Although rotors are carefully designed for fatigue loading and a high level of safety by using high-quality materials and precise manufacturing techniques, catastrophic failures occur in high-speed rotating machines, particularly for the overhung rotor which has considerable weight.

Many researchers have modeled and studied the dynamical responses of overhung rotors using different approaches. Cao et al. [16] studied the nonlinear dynamic behavior of the bladed overhang rotor system with squeeze film damper, using the lumped mass method and the Lagrange approach. Koo et al. [17] presented an analytical method based on transfer relations for an axial flux permanent magnet machine, while taking the overhang length into account. Gong et al. [18] investigated an overhang rotor with two discs supported by a couple of tilting-pad journal bearings. In Gong's work, active lubrication, based on injecting pressurized oil into the bearing gap through orifices machined in the bearing sliding surface, is utilized. Kim et al. [19] considered the overhang effect according to the various rotor types of permanent magnet machine is analyzed by using 3D magnetostatic finite element method. Yu et al. [20] presented a novel outer rotor permanent- 
magnet vernier machine for in-wheel direct-drive application and introduced the overhang structures of the rotor and flux modulation pole. Seo et al. [21] described the analysis and design of a spoke-type motor using ferrite permanent magnet. Kim et al. [22] dealt with the characteristic analysis of the fan motor considering ferrite bonded magnet in an inner-rotor overhang type Brushless DC motor. Noyes et al. [23] used a downwind configuration with a coning angle prescribed to allow load alignment for critical conditions to achieve moment reduction by changing the sign of variables like the overhang. Ma et al. [24] built an overhung rotor-support system to study the dynamic characteristics of rotor and support experimental systems under sudden unbalance excitation. Zhao et al. [25] proposed a permanent magnet vernier machine as a suitable alternative for direct-drive applications due to its high torque feature at a low operated speed and gave out the reasons. Tamrakar et al. [26] conducted an experimental comparison of response for a healthy and cracked overhung rotor system. Tiaki et al. [27] investigated the primary resonances of a cantilever flexible shaft carrying a rigid disk at its free end (overhung rotor). Tamrakar et al. [28,29] presented the response of the overhung rotor on isotropic support and an-isotropic support subject to unbalanced force. All these research works give beneficial results on overhung rotors. However, it is still difficult to conduct the balancing of rotors with a long overhang.

In the field of engineering, to connect with the other parts of a whole system the rotor structures usually have overhang parts whose gravity will introduce moment to the supports. Meanwhile, the nonlinear factors of the rotor system will make this additional moment introduced vibration more complex, i.e., different lengths and position of the overhang will lead to different effects on the vibration of the rotor system. Thus, the motivation of this work is to tackle the problem by modeling, dynamical analysis, statistical analysis and experimentation.

In the following, the modeling process by finite element method will be described in Section 2. Numerical analysis is given in Section 3 and an experimental approach is presented in Section 4. Finally, based on the theoretical and experimental analysis, the discussion and conclusions are given.

\section{Modeling Process}

A rotor with an overhang of $555 \mathrm{~mm}$ length is adopted in this work. A schematic diagram of the rotor with an overhang at the left end support is shown in Figure 1.

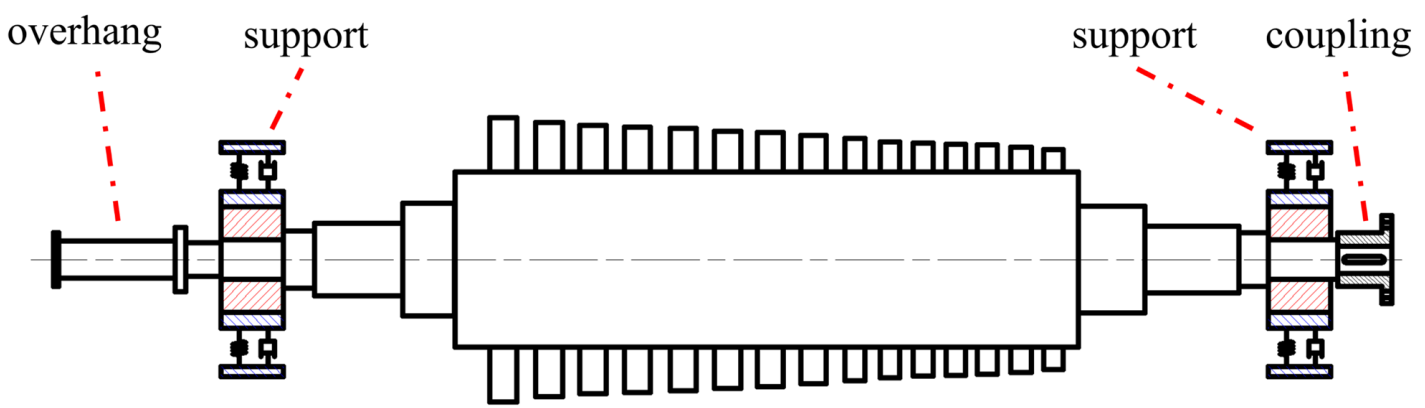

Figure 1. Schematic diagram of the rotor.

In this work, the finite element (FE) method is adopted in the modeling process. By the means of the FE method, the whole system could be meshed into an elements model. Here, the rotor system is divided into rigid discs, elastic shaft segments, and bearing supports. Each element's model can be established separately, then, assembling all the element's matrices together, the stiffness matrix, the mass matrix, and the gyro matrix can be obtained. Based on the FE modeling method, the overhung rotor described by Figure 1 can be discretized into elements with eight nodes, whose positions are given in Figure $2 \mathrm{a}$. 
(a)

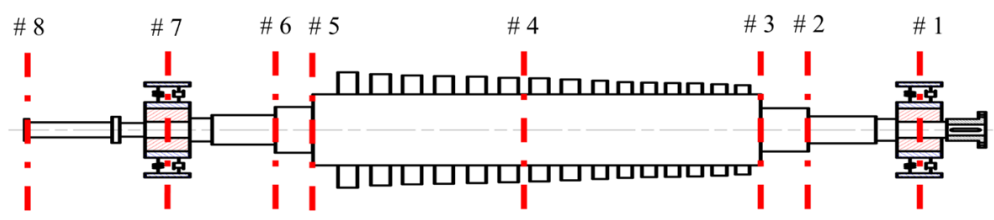

(b)

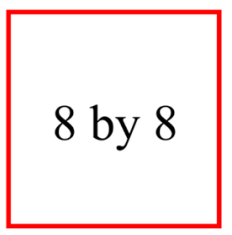

Shaft element matrix

4 by 4

Disc element matrix (if applicable)

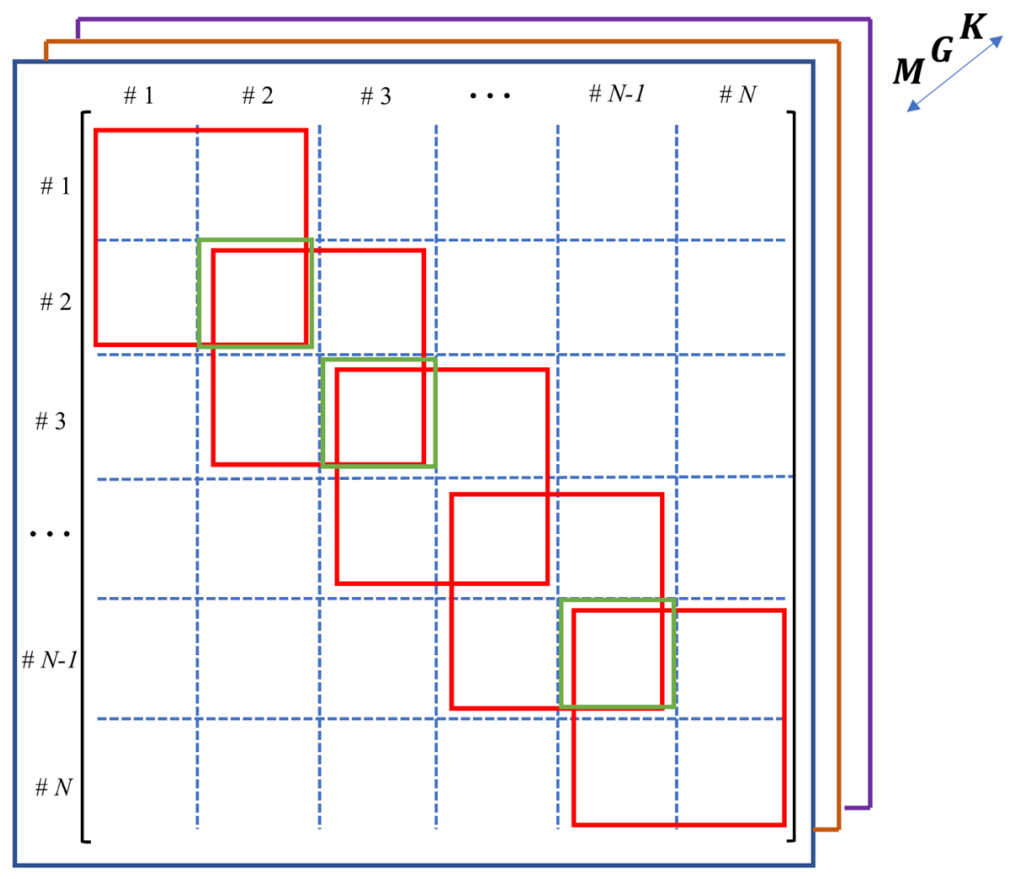

Figure 2. Modeling of the rotor. (a) Meshed model of the rotor, and (b) assembly of the element matrices.

\subsection{Modeling of the Disc}

A rigid disk will be considered as a lumped mass point superposed to the corresponding node. Each one has 4 degrees-of-freedom (DOF), including the vertical direction $(x)$, horizontal direction $(y)$, and the rotating angles along these two directions. Then, the governing equation of the disk can be written in the form

$$
\mathbf{M}_{d} \ddot{\mathbf{q}}_{d}-\omega \cdot \mathbf{G}_{d} \mathbf{q}_{d}=\mathbf{Q}_{d}
$$

where $\mathbf{M}_{d}, \mathbf{G}_{d}$ and $\mathbf{Q}_{d}$ are the equivalent mass, gyro and general force matrices of the chosen node whose expressions are

$$
\begin{aligned}
M_{d} & =\left[\begin{array}{cccc}
m^{d} & 0 & 0 & 0 \\
0 & m^{d} & 0 & 0 \\
0 & 0 & J_{d}^{d} & 0 \\
0 & 0 & 0 & J_{d}^{d}
\end{array}\right] \\
G_{d} & =\left[\begin{array}{cccc}
0 & 0 & 0 & 0 \\
0 & 0 & 0 & 0 \\
0 & 0 & 0 & -J_{p}^{d} \\
0 & 0 & J_{p}^{d} & 0
\end{array}\right]
\end{aligned}
$$

where $m^{d}$ is the mass of the disc, $J_{d}^{d}$ is the equatorial moment of inertia, $J_{p}^{d}$ is the pole moment of inertia. 


\subsection{Modeling of the Shaft Segment}

Choosing the $i$-th elastic beam section, its motion can be described by two nodes with 8 DOFs as

$$
\begin{aligned}
\mathbf{q} & =\left[x_{i}, y_{i}, \theta_{y i}, \theta_{x i}, x_{i+1}, y_{i+1}, \theta_{y(i+1)}, \theta_{x(i+1)}\right]^{T} \\
& =\left[\mathbf{q}_{i}, \mathbf{q}_{i+1}\right]^{T}
\end{aligned}
$$

where $\mathbf{q}_{i}$ represents the $i$-th node's displacement and rotation angle, and $\mathbf{q}_{i+1}$ represents the $(i+1)$-th node's.

$$
\left(\mathbf{M}_{T}^{e}+\mathbf{M}_{R}^{e}\right) \ddot{\mathbf{q}}-\omega \cdot \mathbf{G}^{e} \dot{\mathbf{q}}^{e}+\mathbf{K}^{e} \mathbf{q}^{e}=\mathbf{Q}^{e}
$$

where $\mathbf{M}_{T}^{e}$ and $\mathbf{M}_{R}^{e}$ are mass matrices of the shaft, $\mathbf{G}^{e}$ is the gyro matrix, $\mathbf{K}^{e}$ is the stiffness matrix and $\mathbf{Q}^{e}$ the general force matrix.

The expression of matrices in Equation (3):

$$
\begin{aligned}
& \mathbf{M}_{T}^{e}=\frac{\rho L}{\left(1+\varphi_{s}\right)^{2}}\left[\begin{array}{ccccccccc}
M_{T 1} & & & & & & & \\
0 & M_{T 1} & & & & & & \\
0 & -M_{T 4} & M_{T 2} & & & s y m m & & \\
M_{T 4} & 0 & 0 & M_{T 2} & & & & \\
M_{T 3} & 0 & 0 & M_{T 5} & M_{T 1} & & & \\
0 & M_{T 3} & -M_{T 5} & 0 & 0 & M_{T 1} & & \\
0 & M_{T 5} & M_{T 6} & 0 & 0 & M_{T 4} & M_{T 2} & \\
-M_{T 5} & 0 & 0 & M_{T 6} & -M_{T 4} & 0 & 0 & M_{T 2}
\end{array}\right] \\
& \mathbf{M}_{R}^{e}=\frac{\rho L}{\left(1+\varphi_{s}\right)^{2}}\left(\frac{r_{\rho}}{L}\right)^{2}\left[\begin{array}{ccccccccc}
M_{R 1} & & & & & & & \\
0 & M_{R 1} & & & & & & \\
0 & -M_{R 4} & M_{R 2} & & & s y m m & & \\
M_{R 4} & 0 & 0 & M_{R 2} & & & & \\
-M_{R 1} & 0 & 0 & -M_{R 4} & M_{R 1} & & & \\
0 & -M_{R 3} & M_{R 4} & 0 & 0 & M_{R 1} & & \\
0 & -M_{R 4} & M_{R 3} & 0 & 0 & M_{R 4} & M_{R 2} & \\
M_{R 4} & 0 & 0 & M_{R 3} & -M_{R 4} & 0 & 0 & M_{R 2}
\end{array}\right] \\
& \mathbf{G}^{e}=\frac{\rho r_{\rho}^{2}}{15 L\left(1+\varphi_{s}\right)^{2}}\left[\begin{array}{ccccccccc}
0 & & & & & & & \\
G_{1} & 0 & & & & & & \\
-G_{2} & 0 & 0 & & & \text { antisymm } & & \\
0 & -G_{2} & G_{4} & 0 & & & & \\
0 & G_{1} & -G_{2} & 0 & 0 & & & \\
-G_{1} & 0 & 0 & -G_{2} & G_{1} & 0 & & \\
-G_{2} & 0 & 0 & G_{3} & G_{2} & 0 & 0 & \\
0 & -G_{2} & -G_{3} & 0 & 0 & G_{2} & G_{4} & 0
\end{array}\right] \\
& \mathbf{K}_{T}^{e}=\frac{E I}{L^{2}}\left[\begin{array}{ccccccccc}
K_{B 1} & & & & & & & \\
0 & K_{B 1} & & & & & & \\
0 & -K_{B 4} & K_{B 2} & & & \text { symm } & & \\
K_{B 4} & 0 & 0 & K_{B 2} & & & & \\
-K_{B 1} & 0 & 0 & -K_{B 4} & K_{B 1} & & & \\
0 & -K_{B 1} & K_{B 4} & 0 & 0 & K_{B 1} & & \\
0 & -K_{B 4} & K_{B 3} & 0 & 0 & K_{B 4} & K_{B 2} & \\
K_{B 4} & 0 & 0 & K_{B 3} & -K_{B 4} & 0 & 0 & K_{B 2}
\end{array}\right]
\end{aligned}
$$

in which $E$ is the elastic module, $I$ is the area moment of inertia, $G$ is the shear modulus, $\rho$ is the density, $A$ is the cross-sectional area and $L$ is the length of the shaft segment. Introducing $\varphi_{s}=12 E I /\left(G A L^{2}\right)$ and $r_{\rho}=\sqrt{I / A}$, parameters can be simplified written as $M_{T 1}=$ $13 / 35+7 / 10 \varphi_{s}+1 / 3 \varphi_{s}^{2} ; M_{T 2}=\left(1 / 105+1 / 60 \varphi_{s}+1 / 120 \varphi_{s}^{2}\right) L^{2} ; M_{T 3}=9 / 70+3 / 10 \varphi_{s}+$ 
$1 / 6 \varphi_{s}^{2} ; M_{T 4}=\left(11 / 210+11 / 120 \varphi_{s}+1 / 24 \varphi_{s}^{2}\right) L ; M_{T 5}=\left(13 / 420+3 / 40 \varphi_{s}+1 / 24 \varphi_{s}^{2}\right) L ;$ $M_{T 6}=-\left(1 / 140+1 / 60 \varphi_{s}+1 / 120 \varphi_{s}^{2}\right) L^{2} ; M_{R 1}=6 / 5 ; M_{R 2}=\left(2 / 15+1 / 6 \varphi_{s}+1 / 3 \varphi_{s}^{2}\right) L^{2} ;$ $M_{R 3}=\left(-1 / 30-1 / 6 \varphi_{s}+1 / 6 \varphi_{s}^{2}\right) L^{2} ; M_{R 4}=\left(1 / 10-1 / 2 \varphi_{s}\right) L ; G_{1}=36 ; G_{2}=3 L-15 L \varphi_{s} ;$ $G_{3}=L^{2}+5 L^{2} \varphi_{s}-15 L^{2} \varphi_{s}^{2} ; G_{4}=4 L^{2}+5 L^{2} \varphi_{s}+10 L^{2} \varphi_{s}^{2} ; K_{B 1}=12 /\left(1+\varphi_{s}\right) ; K_{B 2}=$ $L^{2}\left(4+\varphi_{s}\right) /\left(1+\varphi_{s}\right) ; K_{B 3}=L^{2}\left(2-\varphi_{s}\right) /\left(1+\varphi_{s}\right)$ and $K_{B 4}=6 L /\left(1+\varphi_{s}\right)$.

\subsection{Modeling of the Bearing Force}

The simplest way to deal with the bearing element is representing it by a springdamper element. Then the boundary condition of the corresponding node can be decided. However, the nonlinear factors introduced by the bearing force are neglected. To further consider the nonlinear effects, a nonlinear bearing force model is introduced. In this work, a sliding bearing model is adopted. Reynolds' equation is the basic equation for oil film force analysis.

$$
\frac{1}{R^{2}} \cdot \frac{\partial}{\partial \zeta}\left(\frac{h^{3}}{12 \eta} \cdot \frac{\partial p}{\partial \zeta}\right)+\frac{\partial}{\partial z}\left(\frac{h^{3}}{12 \eta} \cdot \frac{\partial p}{\partial z}\right)=\frac{1}{2} \Omega \cdot \frac{\partial h}{\partial \zeta}+\frac{\partial h}{\partial t}
$$

where $R$ is the radius of the journal; $\zeta$ is the clockwise angle from vertical direction; $h$ is the oil film thickness; $\eta$ is the lubricating oil viscosity and $p$ is the oil film pressure. $z$ indicates axial-direction which is neglected in this study and $t$ for time.

Capone's modified oil film force model [30] is applied, and based on which the Equation (4) can be solved analytically. The oil film forces are then obtained with help from Capone's simplification.

$\left\{\begin{array}{l}f_{x} \\ f_{y}\end{array}\right\}=\frac{\left[\left(x-2 y^{\prime}\right)^{2}+\left(y+2 x^{\prime}\right)^{2}\right]^{1 / 2}}{1-x^{2}-y^{2}} \cdot\left\{\begin{array}{l}3 x V(x, y, \alpha)-\sin \alpha G(x, y, \alpha)-2 \cos \alpha S(x, y, \alpha) \\ 3 y V(x, y, \alpha)+\cos \alpha G(x, y, \alpha)-2 \sin \alpha S(x, y, \alpha)\end{array}\right\}$

where

$$
\begin{aligned}
& V(x, y, \alpha)=\frac{2+(y \cos \alpha-x \sin \alpha) G(x, y, \alpha)}{1-x^{2}-y^{2}} \\
& S(x, y, \alpha)=\frac{x \cos \alpha+y \sin \alpha}{1-(x \cos \alpha+y \sin \alpha)^{2}} \\
& G(x, y, \alpha)=\frac{2}{\left(1-x^{2}-y^{2}\right)^{1 / 2}\left[\frac{\pi}{2}+\arctan \frac{y \cos \alpha-x \sin \alpha}{\left(1-x^{2}-y^{2}\right)^{1 / 2}}\right]} \\
& \alpha=\arctan \frac{y+2 x^{\prime}}{x-2 y^{\prime}}-\frac{\pi}{2} \operatorname{sgn}\left(\frac{y+2 x^{\prime}}{x-2 y^{\prime}}\right)-\frac{\pi}{2} \operatorname{sgn}\left(y+2 x^{\prime}\right)
\end{aligned}
$$

where subscript $x$ indicates the vertical component of the oil film force in the radial direction and $y$ the horizontal component of the oil film force in radial direction. $x, y, x^{\prime}$ and $y^{\prime}$ are the general displacements and velocities of corresponding directions.

\subsection{The Governing Equations}

By assembling the corresponding matrices of each node, the mass matrix, the gyro matrix and the stiffness matrix of the whole system can be obtained. The assembled process is described by Figure $2 b$.

Linear damping matrix is adopted as

$$
\mathbf{C}=a \cdot \mathbf{M}+b \cdot \mathbf{K}
$$

where coefficients $a$ and $b$ can be measured by experiment.

Considering the gravity, unbalanced force and bearing force, the dynamic model of the rotor support structure shown in Figure 1 can be established into form

$$
\mathbf{M} \ddot{\mathbf{q}}+(\mathbf{C}+\Omega \mathbf{G}) \dot{\mathbf{q}}+\mathbf{K q}+\mathbf{F}_{n}=\mathbf{F}_{u}+\mathbf{F}_{g}
$$

where $\mathbf{q}$ is the displacement coordinate vector, including the displacements of the two disks and two sliding bearings along the $x$-axis and $y$-axis, respectively; $\mathbf{M}, \mathbf{C}, \mathbf{G}$ and $\mathbf{K}$ are corresponding mass matrix, damping matrix, gyro matrix and stiffness matrix. $\mathbf{F}_{n}$ is the bearing force vector; $\mathbf{F}_{u}$ is the unbalanced force vector and $\mathbf{F}_{g}$ is the gravity vector. $\Omega$ represents the rotating speed of the rotor which determines the frequency of the unbalanced force. 


\section{Numerical Analysis of the System}

Given the dimension of each shaft segment (listed in Table 1) and material properties (listed in Table 2) of the rotor, the simulation of the system described by Equation (7) is carried out to find the dynamical behaviours.

Table 1. The shape value of the shaft.

\begin{tabular}{llllllll}
\hline & Node 1-2 & Node 2-3 & Node 3-4 & Node 4-5 & Node 5-6 & Node 6-7 & Node 7-8 \\
\hline Length & $435 \mathrm{~mm}$ & $235 \mathrm{~mm}$ & $1117.5 \mathrm{~mm}$ & $1117.5 \mathrm{~mm}$ & $185 \mathrm{~mm}$ & $420 \mathrm{~mm}$ & $555 \mathrm{~mm}$ \\
Diameter & $235 \mathrm{~mm}$ & $369 \mathrm{~mm}$ & $588 \mathrm{~mm}$ & $588 \mathrm{~mm}$ & $386 \mathrm{~mm}$ & $252 \mathrm{~mm}$ & $126 \mathrm{~mm}$ \\
\hline
\end{tabular}

Table 2. The material parameter.

\begin{tabular}{ll}
\hline Parameters & Value \\
\hline Young's module $E$ & $100 \times 10^{9} \mathrm{~Pa}$ \\
Density $\rho$ & $7.85 \times 10^{3} \mathrm{~kg} / \mathrm{m}^{3}$ \\
Poisson's ratio $\mu$ & 0.211 \\
Axial force $H$ & 0 \\
\hline
\end{tabular}

\subsection{The Critical Speed of the Rotor with Overhang}

In this subsection, the first three orders of the critical speeds of the rotor system with different stiffnesses are calculated. The common range of the stiffness of the elastic support structure is from $10^{7}$ to $10^{9}$. Thus, here, three represented stiffness values are adopted as $1.5 \times 10^{7}, 1.5 \times 10^{8}$ and $1.5 \times 10^{9}$ in calculation.

The results are listed in Table 3. From Table 3, we find that the stiffness of the elastic support substantially affected the first and second orders, while the third-order critical speed changes little with different stiffnesses. The reason for this is that the frequency of the rigid body mode introduced by elastic support is near the first-order frequency of the bending mode of the rotor. These two modes coupled and represented the first two orders of critical speeds of the rotor.

Table 3. The first three orders critical speed.

\begin{tabular}{llll}
\hline Order of Stiffness & First-Order & Second-Order & Third-Order \\
\hline $10^{7}$ & $13.5 \mathrm{~Hz}$ & $28.5 \mathrm{~Hz}$ & $349.3 \mathrm{~Hz}$ \\
$10^{8}$ & $39.6 \mathrm{~Hz}$ & $86.3 \mathrm{~Hz}$ & $360.9 \mathrm{~Hz}$ \\
$10^{9}$ & $80.6 \mathrm{~Hz}$ & $201.8 \mathrm{~Hz}$ & $416.4 \mathrm{~Hz}$ \\
\hline
\end{tabular}

\subsection{The Correlation Analysis of the Rotor with Overhang}

In this subsection, correlation analysis is conducted as, in design process or control process of a rotor, especially when during balancing process of a rotor structure, not all positions can be measured or adjusted by trial measures. The correlation analysis can help find which position affects most. In this model, the balancing groves are located at node \#3 and node \#5. The position at node \#4 has screw holes. The position at the end of the overhang, which is numbered as node \#8, can also be a position to add trial weight. Two velocity sensors are mounted on the supports (\#1 and \#7). To see the overhang effect, additional eddy current sensor could be applied to measure the displacement of the node $\# 8$. The responses of the nodes \#1,\#7 and \#8 in vertical and horizontal directions of the simulation results with pre-set imbalance at nodes of \#3, \#4, \#5 and \#8 are given from Figures 3-6 separately. 

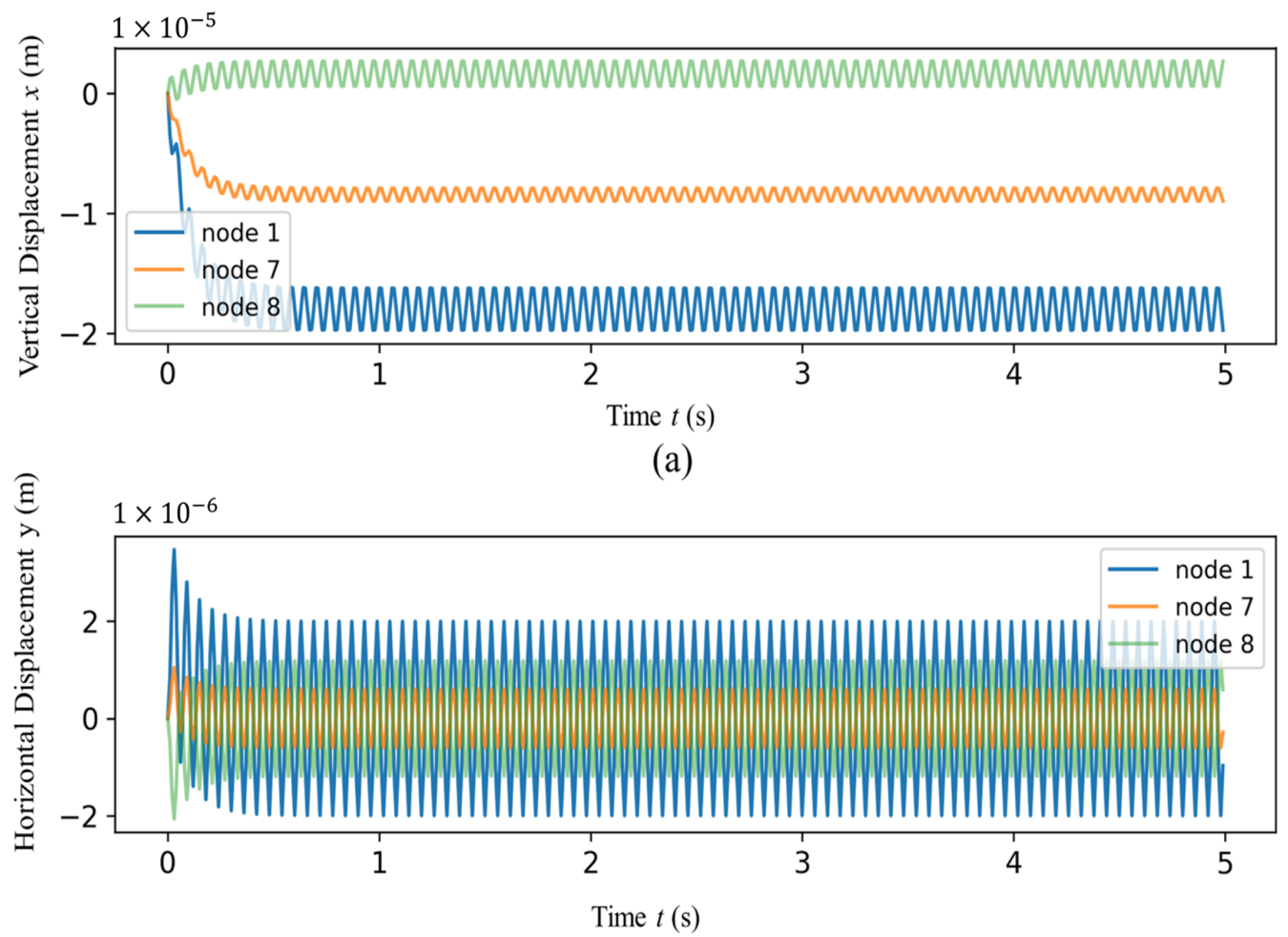

(b)

Figure 3. Responses of the measurable nodes in (a) vertical direction and (b) horizontal direction with pre-set imbalance at node 3 .

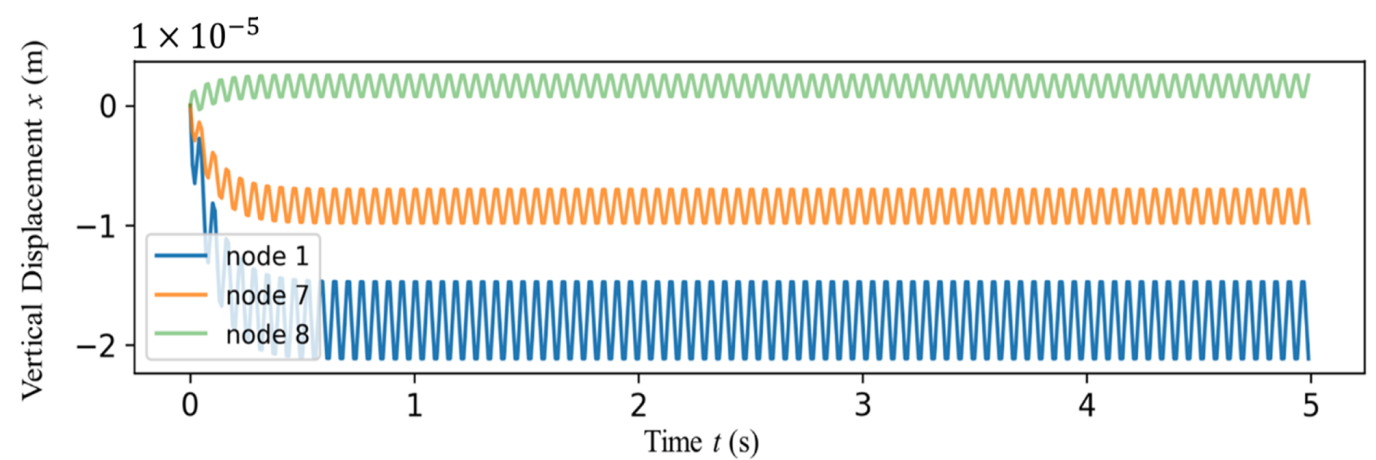

(a)

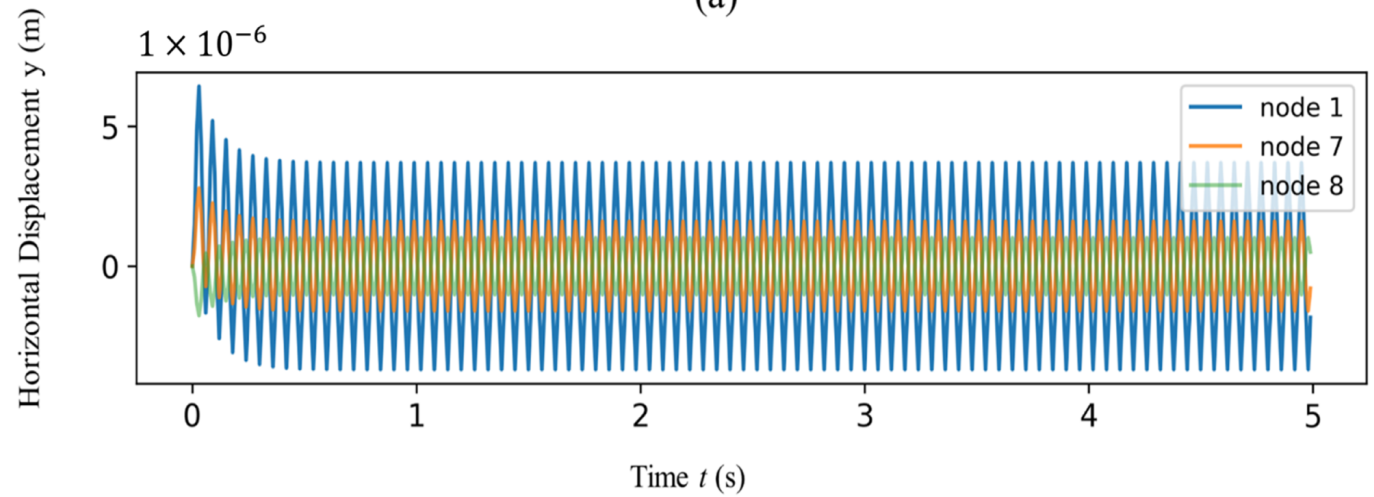

(b)

Figure 4. Responses of the measurable nodes in (a) vertical direction and (b) horizontal direction with pre-set imbalance at node 4 

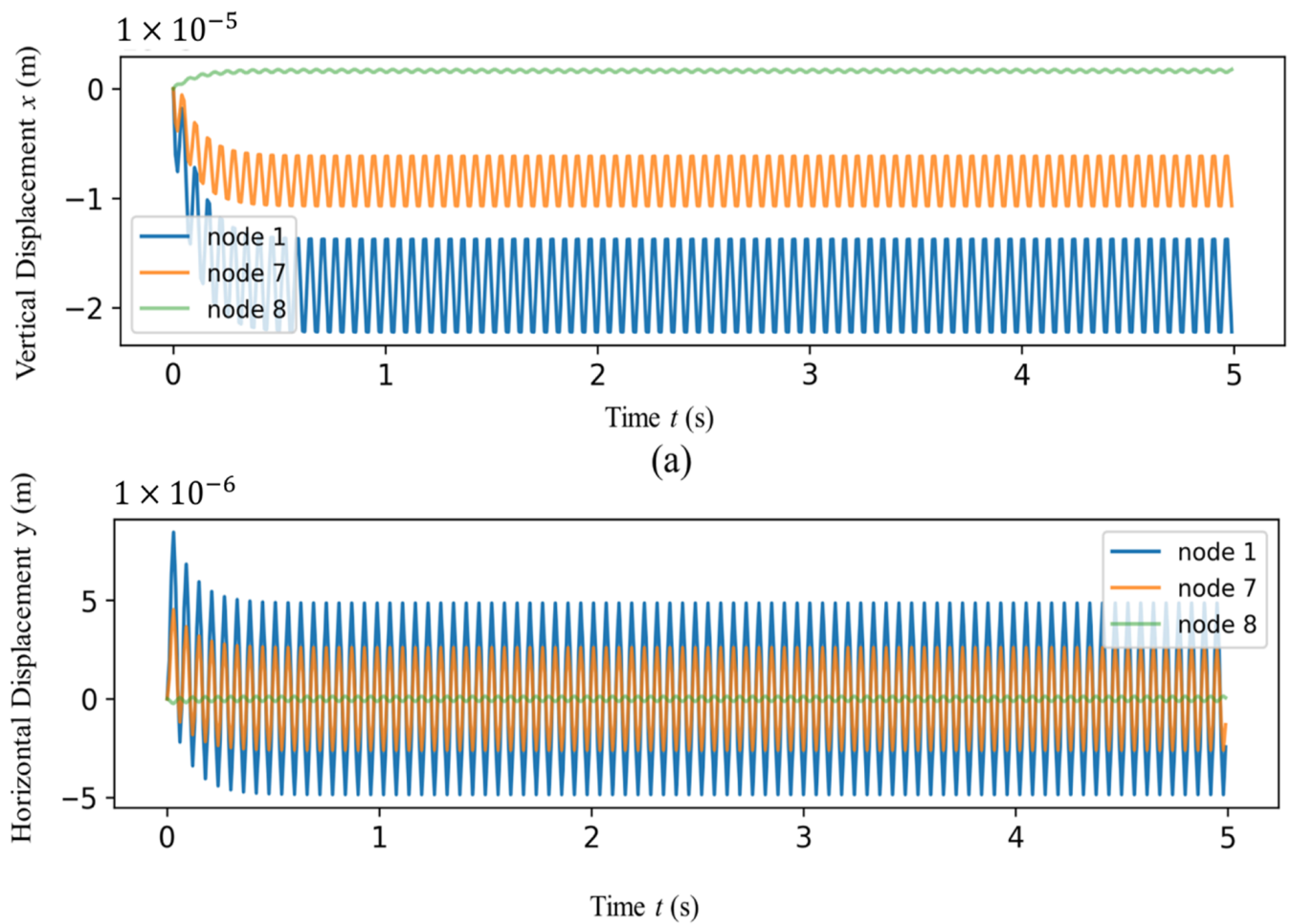

(b)

Figure 5. Responses of the measurable nodes in (a) vertical direction and (b) horizontal direction with pre-set imbalance at node 5 .

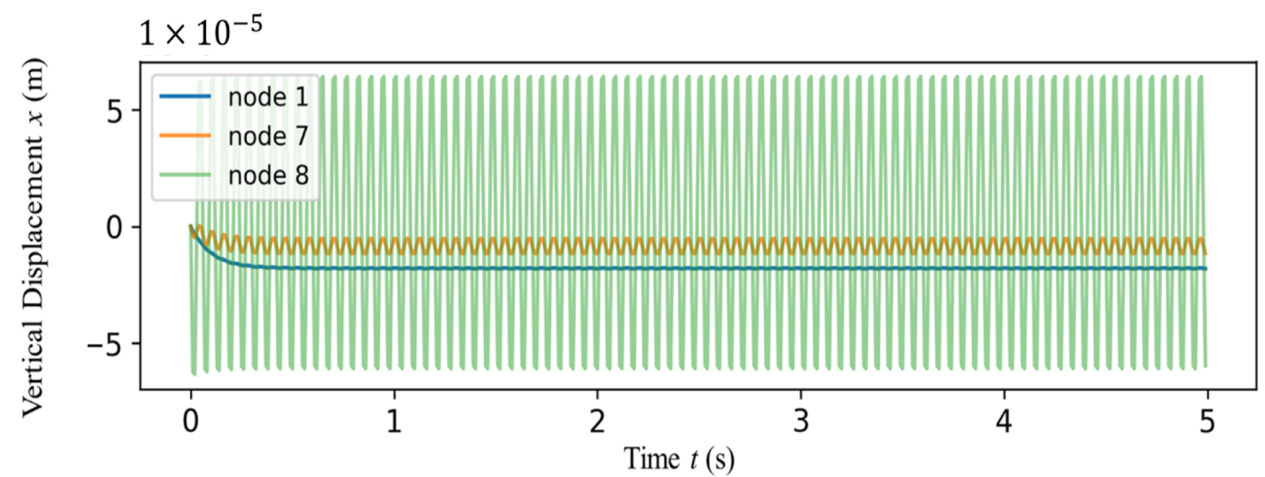

(a)

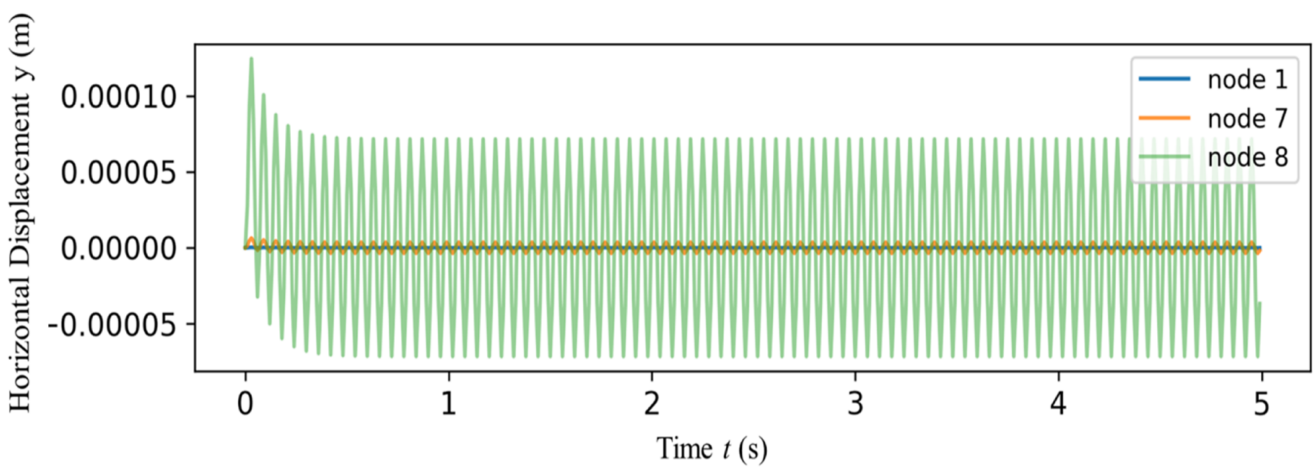

(b)

Figure 6. Responses of the measurable nodes in (a) vertical direction and (b) horizontal direction with pre-set imbalance at node 8 . 
In the simulation study, the pre-set imbalances lead to harmonic type responses, and the gravity makes the vertical mean value not equal to zero. From Figures 3-6, the amplitudes of the responses of different nodes with different pre-set imbalance positions are different. In Figures 3-5, the amplitudes of node 1 are larger than those of node 7. The reason for this phenomenon is that the overhung part has larger effects on node 7 . Introducing a correlation parameter of proportion of amplitude and imbalance, the correlation parameters of different combinations are given in Table 4.

Table 4. The correlation parameter when support stiffness is $10^{9}$.

\begin{tabular}{llll}
\hline \multicolumn{5}{l}{ Correlation $(\mathrm{m} / \mathbf{k g})$} & & \\
\hline & 3 to 1 & 3 to 7 & $0.12 \times 10^{-5}$ \\
$x$ & $0.2 \times 10^{-5}$ & $0.07 \times 10^{-5}$ & $0.13 \times 10^{-5}$ \\
\hline$y$ & $0.22 \times 10^{-5}$ & $0.06 \times 10^{-5}$ & 4 to 8 \\
\hline$x$ & 4 to 1 & 4 to 7 & $0.03 \times 10^{-5}$ \\
$y$ & $0.43 \times 10^{-5}$ & $0.23 \times 10^{-5}$ & $0.03 \times 10^{-5}$ \\
\hline & $0.5 \times 10^{-5}$ & $0.27 \times 10^{-5}$ & 5 to 8 \\
\hline$x$ & 5 to 1 & 5 to 7 & $0.14 \times 10^{-5}$ \\
$y$ & $0.57 \times 10^{-5}$ & $0.38 \times 10^{-5}$ & $0.14 \times 10^{-5}$ \\
\hline$x$ & $0.67 \times 10^{-5}$ & $0.41 \times 10^{-5}$ & 8 to 8 \\
\hline$y$ & 8 to 1 & 8 to 7 & $7.11 \times 10^{-5}$ \\
\hline
\end{tabular}

Following the same method, the correlation parameter when the support stiffnesses are $10^{8}$ and $10^{7}$ are given in Tables 5 and 6.

Table 5. The correlation parameter when support stiffness is $10^{8}$.

\begin{tabular}{llll}
\hline \multicolumn{5}{l}{ Correlation $\mathbf{( m / \mathbf { k g } )}$} & \\
\hline$x$ & 3 to 1 & 3 to 7 & 3 to 8 \\
\hline$y$ & $1.9 \times 10^{-5}$ & $0.65 \times 10^{-5}$ & $0.19 \times 10^{-5}$ \\
& $1.04 \times 10^{-5}$ & $0.64 \times 10^{-5}$ & $0.17 \times 10^{-5}$ \\
\hline$x$ & 4 to 1 & 4 to 7 & 4 to 8 \\
\hline$y$ & $1.79 \times 10^{-5}$ & $1.59 \times 10^{-5}$ & $1.35 \times 10^{-5}$ \\
\hline$x$ & $1.98 \times 10^{-5}$ & $1.74 \times 10^{-5}$ & $1.42 \times 10^{-5}$ \\
\hline$y$ & 5 to 1 & 5 to 7 & 5 to 8 \\
\hline$x$ & $2.6 \times 10^{-5}$ & $2.6 \times 10^{-5}$ & $2.6 \times 10^{-5}$ \\
$y$ & $2.9 \times 10^{-5}$ & $2.9 \times 10^{-5}$ & $2.9 \times 10^{-5}$ \\
\hline
\end{tabular}

Table 6. The correlation parameter when support stiffness is $10^{7}$.

\begin{tabular}{llll}
\hline \multicolumn{5}{l}{ Correlation $(\mathrm{m} / \mathbf{k g})$} \\
\hline 3 to 1 & 3 to 7 & 3 to 8 \\
\hline$x$ & $6.70 \times 10^{-5}$ & $6.68 \times 10^{-5}$ & $6.67 \times 10^{-5}$ \\
$y$ & $8.22 \times 10^{-5}$ & $7.67 \times 10^{-5}$ & $7.30 \times 10^{-5}$ \\
\hline
\end{tabular}


Table 6. Cont.

\begin{tabular}{llll}
\hline \multicolumn{5}{l}{ Correlation $(\mathrm{m} / \mathbf{k g})$} & \\
\hline$x$ & 4 to 1 & 4 to 7 & 4 to 8 \\
\hline$y$ & $1.42 \times 10^{-4}$ & $1.42 \times 10^{-4}$ & $1.42 \times 10^{-4}$ \\
& $1.36 \times 10^{-4}$ & $1.36 \times 10^{-4}$ & $1.36 \times 10^{-4}$ \\
\hline$x$ & 5 to 1 & 5 to 7 & 5 to 8 \\
\hline$y$ & $2.16 \times 10^{-4}$ & $2.38 \times 10^{-4}$ & $2.74 \times 10^{-4}$ \\
\hline$x$ & $1.98 \times 10^{-4}$ & $2.21 \times 10^{-4}$ & $2.57 \times 10^{-4}$ \\
\hline$y$ & 8 to 1 & 8 to 7 & 8 to 8 \\
\hline
\end{tabular}

\section{Experimental Test}

\subsection{Experiment Descriptions}

The experiment is carried out by a real generator rotor. Figure 7 gives the pictures of the experiment rotor (a) and supports used (b). In Figure 7a, agreeing with the FE model described in Figure 2a, nodes \#1 and \#7 are supported by the supports described by Figure $7 \mathrm{~b}$. The \#3, \#4, \#5 and \#8 are four nodes where trail weights can be added. The supports shown in Figure $7 \mathrm{~b}$ have an equivalent stiffness of $4.5 \times 10^{8} \mathrm{~N} / \mathrm{m}$ and have velocity sensors to test the journal vibration.

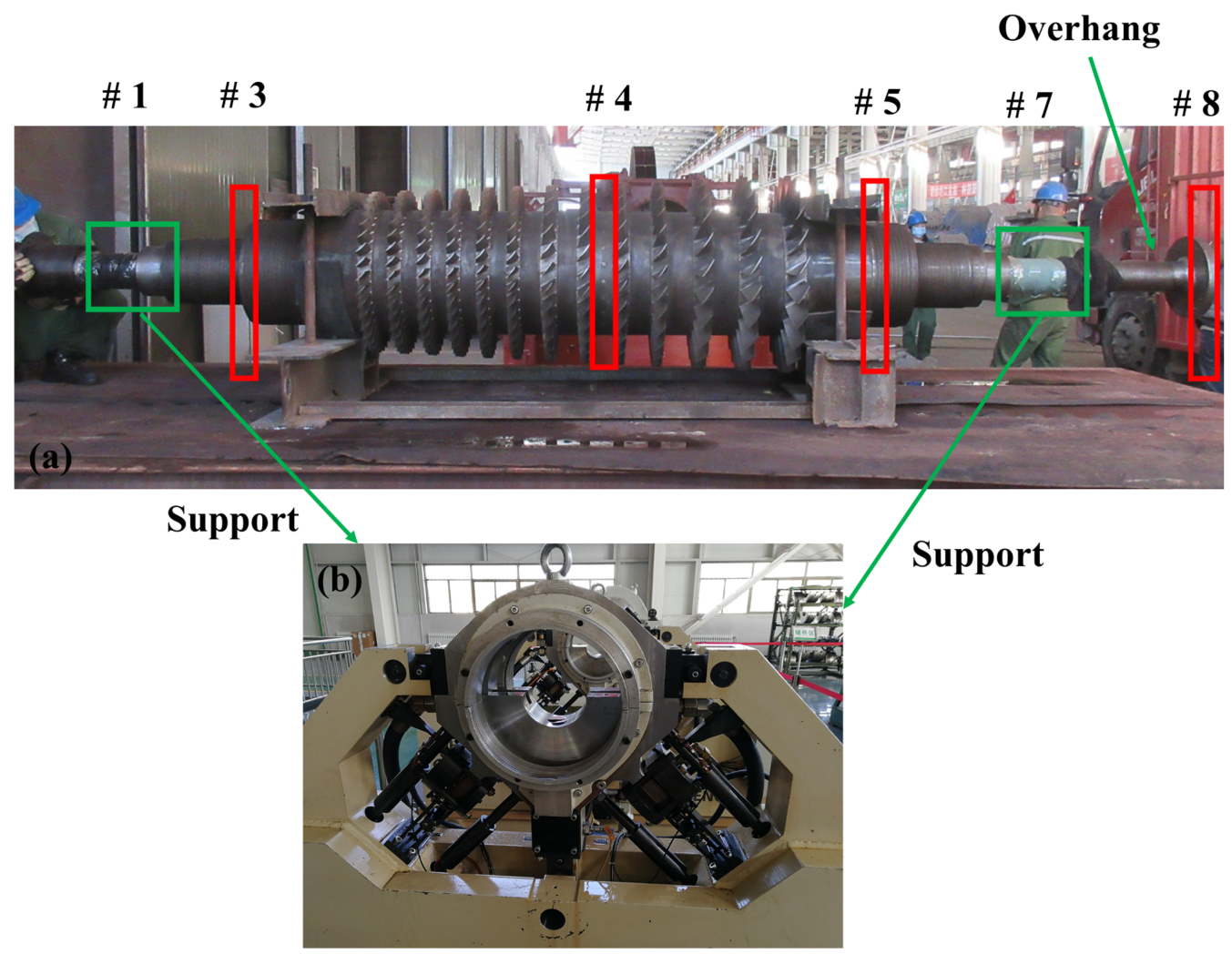

Figure 7. The experimental rotor and supports. (a) The rotor and (b) The support pedal. (\#1 and \#7 are the nodes where supported by support shown in (b) and \#3, \#4, \#5 and \#8 are nodes where trial weights can be added).

\subsection{Experiment Procedure}

Figure 8 gives the initial measured results. The Bode diagrams of the responses of the two support pedals are plotted in Figure 8, where red color lines indicate the curves of the 
root mean square (rms) of the responses with respect to the rotating speed of pedal 1 (\#1) and black lines correspond to pedal 2 (\#7). For both colours, the solid line represents the run-up process and the dotted line the run-down process. The working speed is expected at $6500 \mathrm{rpm}$, but the value of vibration amplitude of pedal 2 reaches the safe limit at a speed of around $5500 \mathrm{rpm}$. So the first test stops.

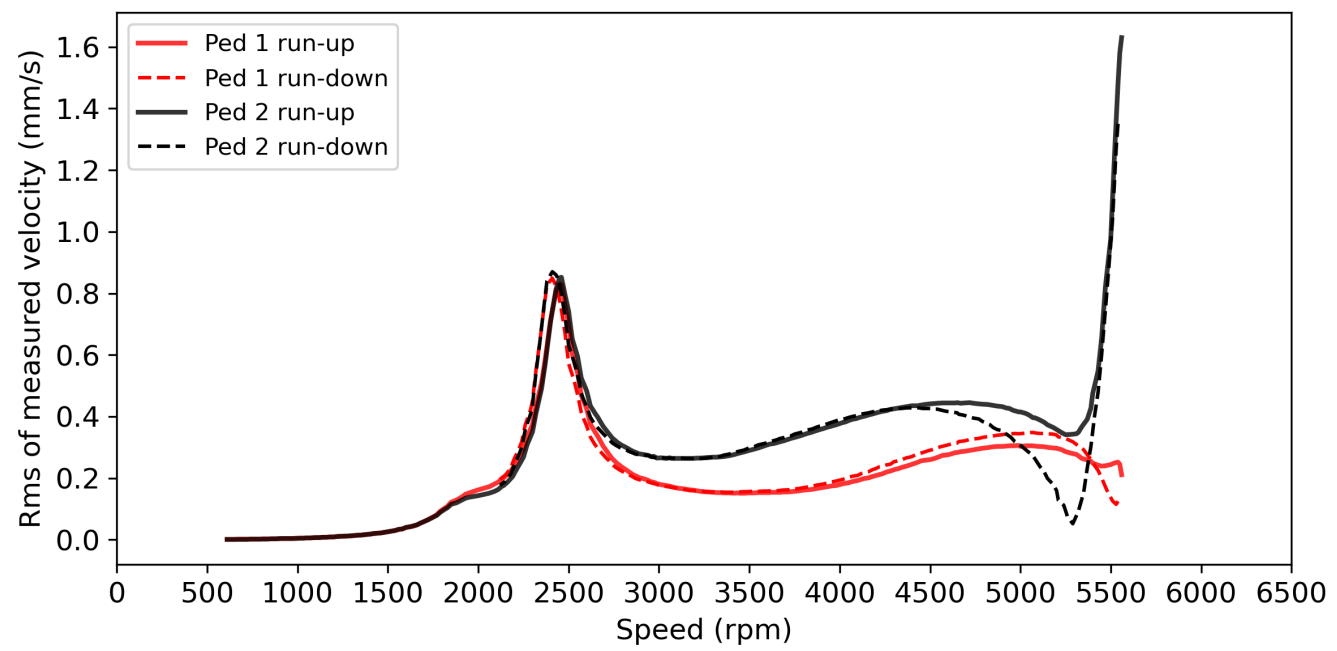

Figure 8. Bode diagram of the responses at the nodes of supports when no trail weight is added.

Based on the initial measured result and the traditional rotor balancing method, a $50 \mathrm{~g}$ trail weight on the middle of the rotor (\#5) is applied. Figure 9 gives the Bode diagrams of the responses of pedals 1 and 2 when $50 \mathrm{~g}$ trail weight is added. However, the vibrations are not suppressed, but a little amplified when the rotating speed approaches the second-order resonance region.

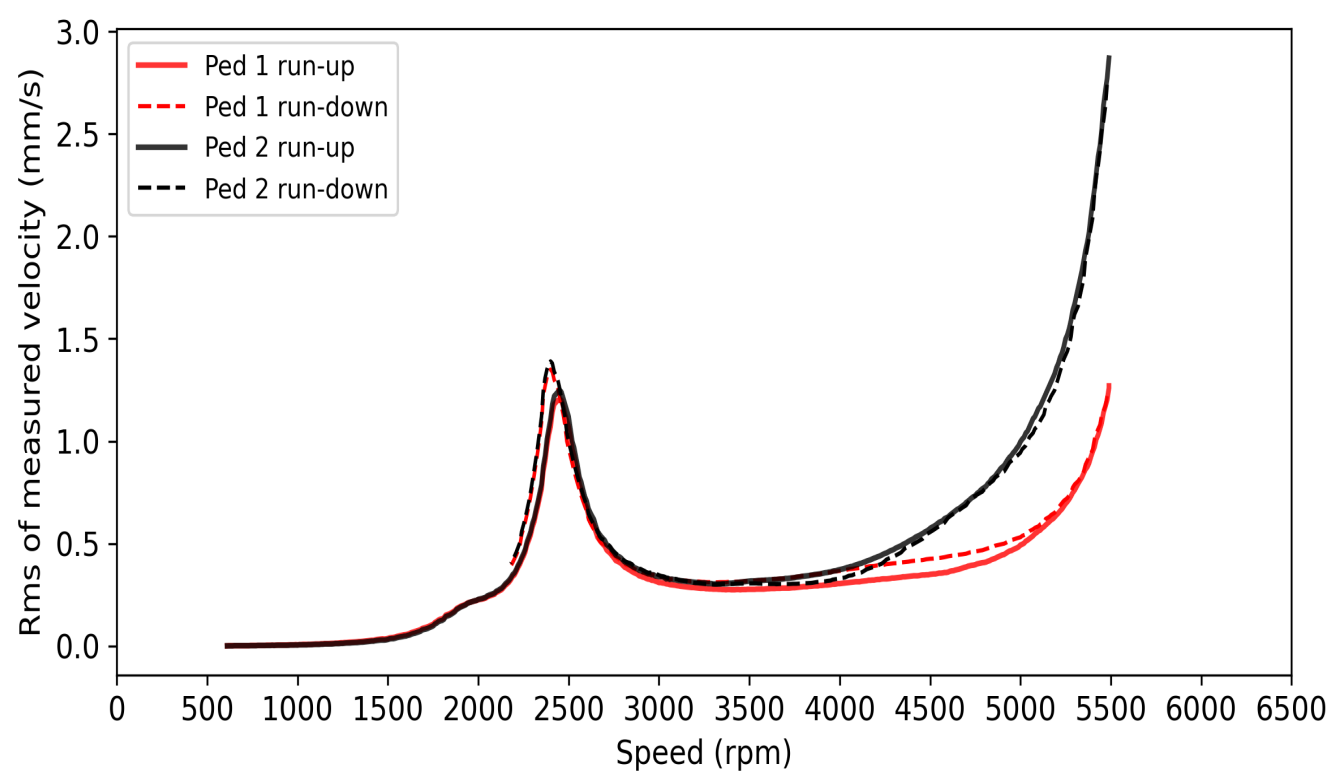

Figure 9. Bode diagram of the responses at the nodes of supports when $50 \mathrm{~g}$ trail weight is added on the \#4.

Based on the correlation analysis conducted in the previous section, the trail weight added on the \#5 node has an almost equal effect on measured points. Therefore, it is not a good position to balance the rotor with an overhang, although it is the first choice for a 
symmetry rotor as it is the peak point of the first-order modal function. Thus, the overhang part of the rotor is chosen to be the next trial position. A $2 \mathrm{~g}$ trail weight is added and the corresponding Bode diagrams are shown in Figure 10.

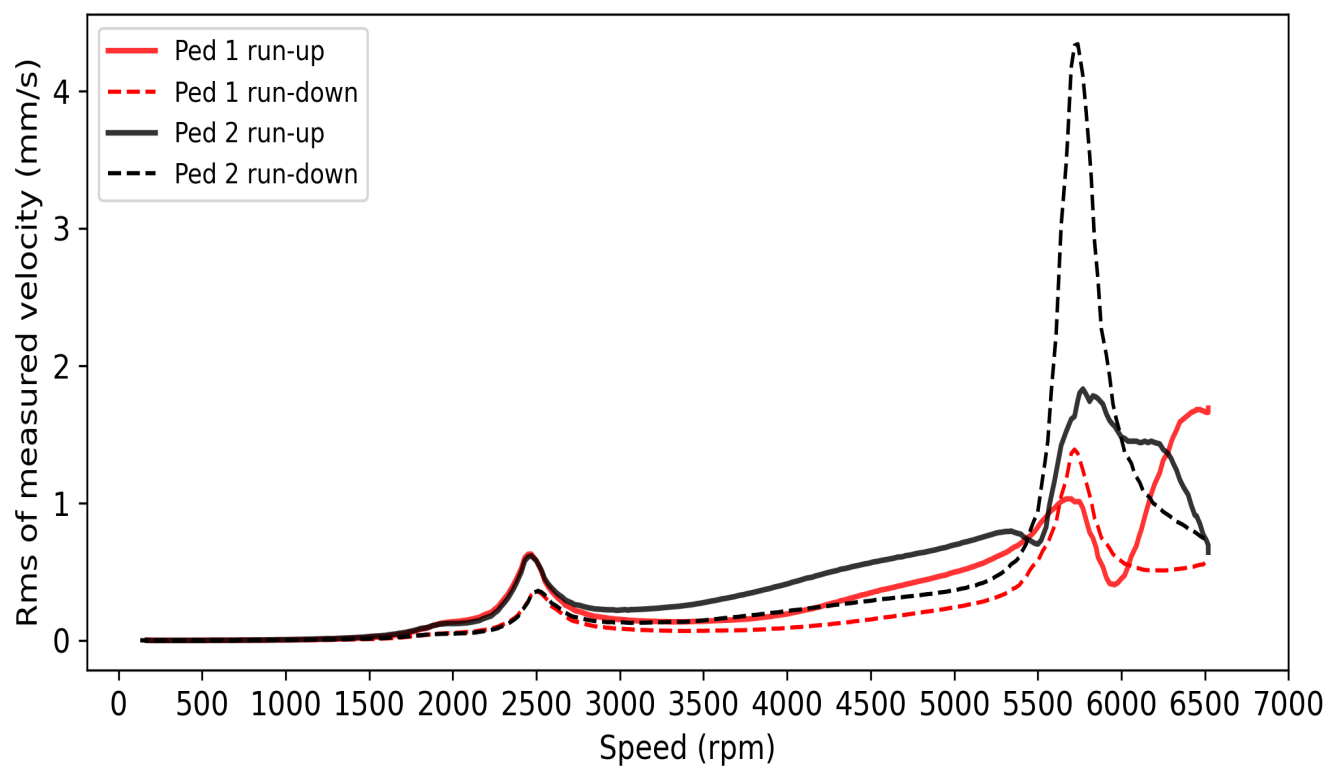

Figure 10. Bode diagram of the responses at the nodes of supports when $2 \mathrm{~g}$ trail weight is added on the \#8.

This time, the peak values of the first-order and second-order main resonance are suppressed. However, the value of pedal 1 is still beyond the limit at the working speed. It can be noted that the position has a significant effect. Only the mass of the trail weight needs to be adjusted further.

Figure 11 gives the Bode diagram of the measured responses with $4 \mathrm{~g}$ trail weight. After a small change in the mass of the trail weight, the responses of the rotor satisfy the working limits.

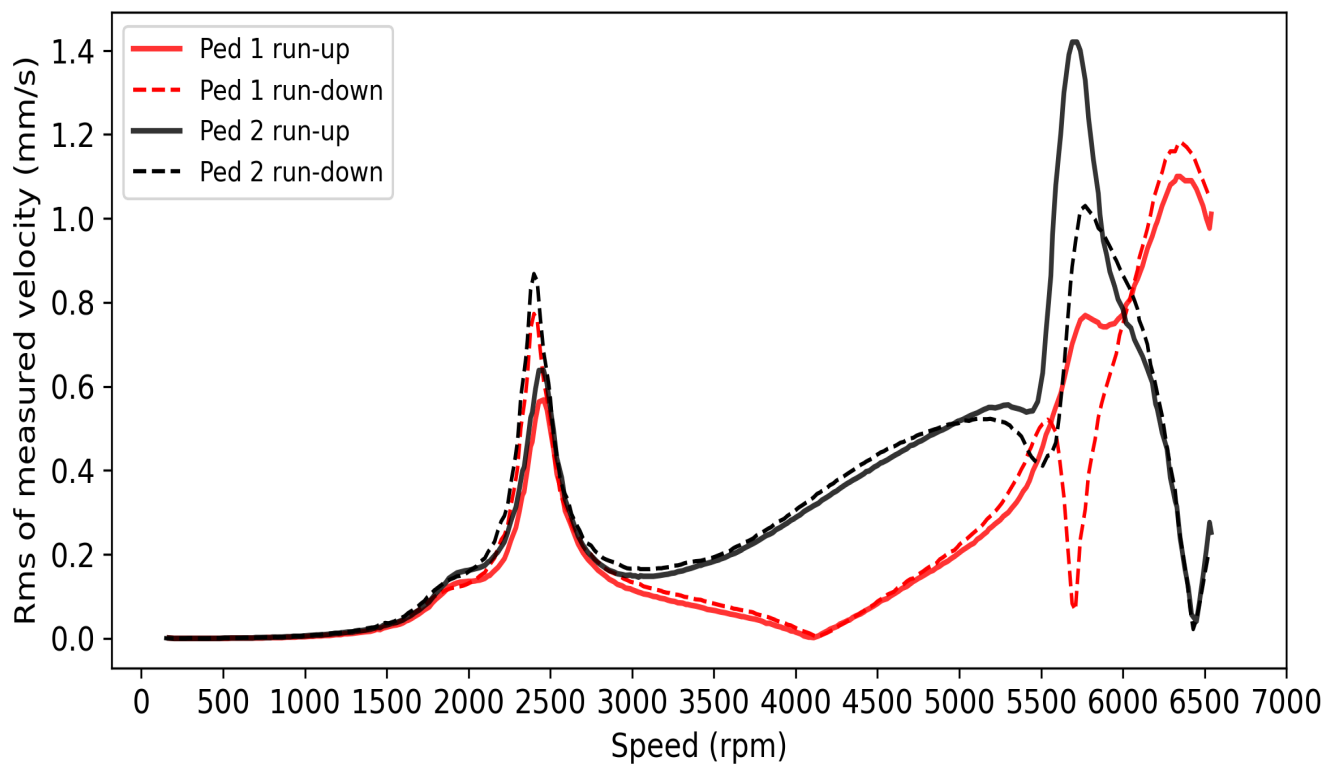

Figure 11. Bode diagram of the responses at the nodes of supports when $4 \mathrm{~g}$ trail weight is added on the \#4. 


\section{Discussion and Conclusions}

For a rotor without overhang, many balancing methods have been proposed to identify the imbalance distribution. However, for an overhang rotor, methods are seldom proved to be suitable. In the field of engineering, rotors with long overhangs are considered impossible to balance. Most of the time, to suppress the vibration of this kind of rotor, the rotor structure or the position of support are adjusted. According to the correlation analysis, a rotor with overhang can be easily balanced. Compared with the modal based balancing method, the correlation analysis are simple and implementable.

In this work, modeling, dynamical simulation, correlation analysis and experiment of an overhung rotor are carried out. Based on the rules found, we could conclude that (1) The critical speeds of the first and the second orders are substantially affected by support stiffnesses and the coupling effect of the bearing and support stiffnesses, while the third order is less affected by the reasonable stiffness range; and (2) By introducing a correlation parameter, which is defined by imbalance mass and amplitude of the particular nodes, the most influenced nodes can be found. With the rotor model adopted in this work, the overhung node is most influential.

Based on the findings, by choosing the overhang node to add trial weight, an overhung rotor is easily balanced. Through experimental testing, this analysis has significant meaning in terms of controlling the vibration of the overhang rotor. The theory provides an alternative approach to modal analysis which needs more knowledge of the system.

Author Contributions: Conceptualization, S.Z. (Shun Zhong), S.Z. (Suxia Zhang); methodology, S.Z. (Shun Zhong), J.Y. and Y.Z.; software, S.Z. (Shun Zhong); validation, S.Z. (Shun Zhong), J.Y. and Y.Z.; formal analysis, S.Z. (Shun Zhong); investigation, S.Z. (Shun Zhong), J.Y. and Y.Z.; writing-original draft preparation, S.Z. (Shun Zhong); writing-review and editing, S.Z. (Shun Zhong); visualization, S.Z. (Shun Zhong); supervision, S.Z. (Suxia Zhang); project administration, S.Z. (Suxia Zhang); funding acquisition, S.Z. (Suxia Zhang). All authors have read and agreed to the published version of the manuscript.

Funding: This work was supported by the National Natural Science Foundation of China (Grant nos. 51479136,12102234, 11902184, 11502161),the Project of Tianjin Municipal Transportation Commission (2019-15), and the Project of Tianjin Natural Science Foundation (17JCYBJC18700).

Institutional Review Board Statement: Not applicable.

Informed Consent Statement: Not applicable.

Data Availability Statement: Restrictions apply to the availability of these data. Data was obtained from Hebei Ruizhao Laser Remanufacturing Technology Stock Co., Ltd and are available from Yang Jie with the permission of Hebei Ruizhao Laser Remanufacturing Technology Stock Co., Ltd.

Conflicts of Interest: On behalf of all authors, the corresponding author states that there is no conflict of interest.

\section{References}

1. Shin, H.; Shin, K.; Jang, G.; Cho, S.; Jung, K.; Choi, J. Experimental Verification and 2D Equivalent Analysis Techniques of BLDC Motor With Permanent Magnet Overhang and Housing-Integrated Rotor Core. IEEE Trans. Appl. Supercond. 2020, 30, 1-5. [CrossRef]

2. Petukhov, I.; Akinin, K.; Filomenko, A. Influence of the Magnetic Field of the Overhang Parts of the Micromotor Winding on the Rotor Position Sensor. In Proceedings of the 2020 IEEE Problems of Automated Electrodrive. Theory and Practice (PAEP), Kremenchuk, Ukraine, 21-25 September 2020; pp. 1-4.

3. Lee, J.; Kim, R.; Jung, H.; Yeo, H. Electromagnetic and thermal analyses of surface-mounted permanent magnet motor with flux-absorbing structure for enhancing overhang effect. IET Electr. Power Appl. 2020, 14, 2037-2043. [CrossRef]

4. Shin, H.; Jang, G.; Choi, J. Quasi-3D electromagnetic analysis and experimental verification of multi-pole magnetization BLDC motor. AIP Adv. 2020, 10, 015218. [CrossRef]

5. Fedorynenko, D.; Kirigaya, R.; Nakao, Y. Dynamic characteristics of spindle with water-lubricated hydrostatic bearings for ultra-precision machine tools. Precis. Eng. 2020, 63, 187-196. [CrossRef]

6. Yao, S.; Griffith, D.T.; Chetan, M.; Bay, C.J.; Damiani, R.; Kaminski, M.; Loth, E. A gravo-aeroelastically scaled wind turbine rotor at field-prototype scale with strict structural requirements. Renew. Energy 2020, 156, 535-547. [CrossRef] 
7. Hwang, Y.J.; Jang, J.Y.; Jeon, H. Overhang Effect Analysis of a Homopolar HTS Synchronous Generator Using 3D Finite Element Method. IEEE Trans. Appl. Supercond. 2020, 30, 1-5. [CrossRef]

8. Bak, C.; Forsting, A.M.; Sorensen, N.N. The influence of leading edge roughness, rotor control and wind climate on the loss in energy production. J. Phys. Conf. Ser. 2020, 1618, 052050. [CrossRef]

9. Shin, K.; Bang, T.; Cho, H.; Choi, J. Design and Analysis of High-Speed Permanent Magnet Synchronous Generator With Rotor Structure Considering Electromechanical Characteristics. IEEE Trans. Appl. Supercond. 2020, 30, 1-5. [CrossRef]

10. Ludecke, F.D.; Cheng, P.W. Simplified design criteria for drivetrains in direct-drive wind turbines. J. Phys. Conf. Ser. 2020, 1618, 042024. [CrossRef]

11. Ferede, E.; Gandhi, F. Aeroelastic Analysis of a Quad-Rotor Wind Turbine. In Proceedings of the AIAA Scitech 2021 Forum, Nashville, TN, USA, 11-15 January 2021; p. 0813.

12. Filsoof, O.T.; Hansen, M.H.; Yde, A.; Bottcher, P.; Zhang, X. A novel methodology for analyzing modal dynamics of multi-rotor wind turbines. J. Sound Vib. 2021, 493, 115810. [CrossRef]

13. Ortolani, A.; Persico, G.; Drofelnik, J.; Jackson, A.; Campobasso, M.S. High-fidelity calculation of floating offshore wind turbines under pitching motion. In Turbo Expo: Power for Land, Sea, and Air; American Society of Mechanical Engineers: New York, NY, USA, 2020; Volume 84249, p. V012T42A012.

14. Kumar, C.V.S.; Vivek, E.K.; Vignesh, S. Rotordynamic Analysis and Redesign of High-Pressure Turbine Test Rig. In Proceedings of the 6th National Symposium on Rotor Dynamics; Springer: Berlin/Heidelberg, Germany, 2021; pp. 77-91.

15. Van der Male, P.; Van Schaik, R.; Vergassola, M.; van Dalen, K.N. Tower shadow excitation of a downwind rotor blade of a turbine with a tubular tower. J. Phys. Conf. Ser. 2020, 1618, 032019. [CrossRef]

16. Cao, D.; Wang, L.; Chen, Y.; Huang, W. Bifurcation and chaos of the bladed overhang rotor system with squeeze film dampers. Sci. China Ser. E Technol. Sci. 2009, 52, 709-720. [CrossRef]

17. Koo, M.; Choi, J.; Park, Y.; Jang, S. Influence of rotor overhang variation on generating performance of axial flux permanent magnet machine based on 3-D analytical method. IEEE Trans. Magn. 2014, 50, 1-5. [CrossRef]

18. Gong, X.; Cao, D. Fuzzy proportional-integral-derivative control of an overhang rotor with double discs based on the active tilting pad journal bearing. J. Vib. Control 2013, 19, 1487-1498. [CrossRef]

19. Kim, K.; Lee, J. Overhang effect analysis of permanent magnet machine according to the rotor types. In Proceedings of the 2006 12th Biennial IEEE Conference on Electromagnetic Field Computation, Miami, FL, USA, 30 April-3 May 2006; pp. 414-414.

20. Yu, D.; Huang, X.; Wu, L.; Fang, Y. Design and Analysis of Outer Rotor Permanent-Magnet Vernier Machines with Overhang Structure for In-Wheel Direct-Drive Application. Energies 2019, 12, 1238. [CrossRef]

21. Seo, J.; Ro, A. Analysis and Design of Spoke-type Ferrite Permanent Magnet Motor with Rotor Overhang. In Proceedings of the 2018 IEEE 18th International Power Electronics and Motion Control Conference (PEMC), Budapest, Hungary, 26-30 August 2018; pp. 512-517.

22. Kim, H.; Jung, T. Analysis of rotor overhang effect considering load torque variance in automobile BLDC fan motor. In Proceedings of the 2012 IEEE Vehicle Power and Propulsion Conference, Seoul, Korea, 9-12 October 2012; pp. 68-71.

23. Noyes, C.; Qin, C.; Loth, E. Pre-aligned downwind rotor for a $13.2 \mathrm{MW}$ wind turbine. Renew. Energy 2018, 116, 749-754. [CrossRef]

24. Ma, Y.; Liang, Z.; Zhang, D.; Yan, W.; Hong, J. Experimental investigation on dynamical response of an overhung rotor due to sudden unbalance. In Turbo Expo: Power for Land, Sea, and Air; American Society of Mechanical Engineers: New York, NY, USA, 2015; Volume 56772, p. V07BT32A009.

25. Zhao, F.; Kwon, B. Optimal design of asymmetric rotor overhang lengths in an axial-flux dual-stator permanent magnet vernier machine. In Proceedings of the 2015 IEEE International Magnetics Conference (INTERMAG), Beijing, China, 11-15 May 2015; p. 1.

26. Tamrakar, R.; Mittal, N.D.; Singh, R.K. Experimental Comparison of Response for Healthy and Cracked Overhung Rotor System. Arab. J. Sci. Eng. 2021, 46, 11701-11710. [CrossRef]

27. Tiaki, M.M.; Hosseini, S.A.A.; Zamanian, M. Nonlinear forced vibrations analysis of overhung rotors with unbalanced disk. Arch Appl. Mech. 2016, 86, 797-817. [CrossRef]

28. Tamrakar, R.; Mittal, N.D. Comparison of response to unbalance of overhung rotor system for different supports. Int. J. Mech. Eng. Technol. 2017, 8, 56-65.

29. Tamrakar, R.; Mittal, N.D. Crack detection in an overhung rotor system using external harmonic excitation. In Advances in Rotor Dynamics, Control, and Structural Health Monitoring; Springer: Berlin/Heidelberg, Germany, 2020; pp. 159-169.

30. Capone, G. Analytical description of fluid-dynamic force field in cylindrical journal bearing. L'Energia Elettr. 1991, 3, 105-110. 